\title{
TRAJETÓRIA RECENTE E CONTRIBUIÇÕES PARA O CONHECIMENTO EM ADMINISTRAÇÃO
}

\section{Maria Ceci Misoczky ${ }^{1}$}

http://dx.doi.org/10.1590/1413-2311.251.95321

Escrevo este Editorial no momento em que encerro meu período como Editora da Revista Eletrônica de Administração - REAd. Nestes dois anos, realizamos diversas alterações, sendo a mais importante a afirmação de uma nova linha editorial que valoriza trabalhos que contribuam para o avanço do conhecimento e, por exemplo, inclui a aceitação de ensaios em substituição a artigos de revisão. Com isso, ampliamos espaços para a reflexão argumentativa com qualificada fundamentação teórica e diversificamos as perspectivas ontoepistemológicas. Continuamos sendo uma Revista de Administração, e valorizamos essa característica. No entanto, ressaltamos que os trabalhos empíricos precisam, para além de sua contribuição para a prática, contribuir também para o conhecimento sobre o tema e isso se faz desde uma forte articulação teórico-empírica.

Depois de muito tempo, retomamos a organização de um dossiê a partir de uma chamada de trabalhos sobre 'Administração Pública e Neoliberalismo na América Latina e no Caribe no Século XXI'. Tivemos a honra de receber um trabalho do Professor Omar Guerrero, com o qual decidimos iniciar o dossiê. Para o público brasileiro que, em parte, pode não conhecê-lo, destaco que se trata de um autor com mais de três décadas de trabalho e produção científica. Graduado em Ciência Política e Administração Pública, Doutor em Administração Pública, Professor Titular da Faculade de Ciências Políticas e Sociais da Universidade Nacional Autónoma de México (UNAM), é autor de cerca de 30 livros e foi um dos primeiros a refletir criticamente sobre o que viria a ser a perspectiva hegemônica da Nova Administração Pública. O livro ‘Del Estado Gerencial al Estado Cívico’, publicado em 1999, é um marco na reflexão sobre esse tema.

\footnotetext{
${ }^{1}$ Universidade Federal do Rio Grande do Sul - Escola de Administração de Brasília; Rio Grande do Sul - Porto Alegre (Brasil) - http://orcid/org/0000-0003-2020-5882. Correio Eletrônico: maria.ceci@ufrgs.br.
} 
Após o artigo do Prof. Guerrero, sobre Neoliberalismo e Nova Gestão Pública, segue um artigo convidado, de autoria dos proponentes da chamada de trabalhos - Paulo Abdala e José Fransciso Puello-Socarrás -, que se constitui em uma reflexão teórica e funciona como uma espécie de pano de fundo para os artigos que seguem e que, como é característica da Revista, expressam diversos temas e perspectivas, bem como contextos nacionais e políticos: o emprego público na aspiração de modernizar o Estado no governo de Mauricio Macri (2015-2019) na Argentina, de autoria de Gustavo Blutman e Agustín Hoya; Manuel Yañez também se refere a esse contexto, mas aborda a privatização nas políticas para empresas públicas; ampliando a abrangência, Camilo Peña Ramirez, Barbara Andrea Arias Mora, Sheila Serafim da Silva e Marcelo Gonçalves do Amaral analisam o capital intelectual em incubadoras de empresas e os efeitos de diferentes indicadores em relação ao seu sucesso, em um estudo que incluiu 39 incubadoras de 7 países (Argentina, Bolívia, Chile, México, Paraguai, Peru e Uruguai); finalmente, Jonatas Dutra Sallaberry e Leonardo Flach analisam a influência do poder econômico nas eleições nacionais brasileiras de 2018.

Entre os artigos publicados que foram submetidos no fluxo contínuo, iniciamos com três que poderiam, perfeitamente, fazer parte do dossiê, tendo em vista a proximidade temática. No primeiro, Elcemir Paço Cunha argumenta que a centralidade da gestão para a administração política não a difere com relação ao chamado mainstream, mantendo a mesma redução dos problemas sociais meros problemas de gestão, e propõe uma retomada da relação entre a gestão do Estado e as contradições sociais; no segundo, Douglas Arrais Melo e Hélio Yochihiro Fuchigami propõem um índice bidimensional de transparência da informação público-eletrônica como ferramenta para participação e controle sociais orientado aos sítios eletrônicos das universidades federais; no terceiro, Jailson Ribeiro Soares, Ronaldo Bordin e Roger dos Santos Rosa avaliam os resultados dos nove indicadores de gestão propostos pelo Tribunal de Contas da União e dos indicadores de qualidade das Instituições Federais de Ensino Superior (IFES), no período 2009-2016, identificando as variáveis que mais impactam no indicador de qualidade. Para fechar esse número e corroborando o amplo escopo da Revista em sua inserção na área da Administração, Carolina Araujo Forleo e Luiz Antonio Slongo analisam os grupos de referência valorizados por consumidoras de baixa renda.

Um aspecto importante neste período de editoria foi ter assumido claramente a opção de sermos uma Revista de Administração. Há uma discussão relevante sobre a Administração como uma área que priviliegia a prática, sendo eminentemente prescritiva e funcionalista, em contraposição ao caráter analítico, construtivista ou crítico que pode ser desenvolvido, por exemplo, nas Teorias e nos Estudos Organizacionais. Martínez, Lários e Albuquerque (2011), 
chegam a levantar a possibilidade de que essas perspectivas possam se constituir na consciência teórica da Administração. Penso que estamos demonstrando, com o apoio de todos os que contribuem para a concretização da Revista (destacando os avaliadores, a quem agradeço por sua responsabilidade e qualificação) que é possível manter-se no escopo amplo da nossa grande área, sempre evidenciando a diversidade de vertentes onto-epistemológicas que a definem. Para tanto, estabelecemos como critério que, respeitando essa diversidade, é indispensável superar textos descritivos e/ou que apenas aplicam corpos teóricos estabelecidos, e valorizar trabalhos que contribuem para o avanço do conhecimento sobre os temas que abordam, a partir de textos empírico-analíticos ou ensaísticos com qualificada sustentação teórica.

Trabalhamos em um cenário de muitos desafios e crescentes dificuldades que, como constatamos diariamente, se ampliam e ameaçam as instituições públicas de ensino e pesquisa e, portanto, nossos instrumentos de divulgação do conhecimento científico. Também nos encontramos em um momento de alterações no portal Scielo, com o projeto 'Ciência Aberta', com a nova versão da plataforma SEER, com o dinamismo nas lógicas de indexação e em pleno processo de finalização da nova classificação Qualis-Capes. Ou seja, um período no qual se associarão, de maneira não harmoniosa, novos desafios e tarefas, por um lado, e restrição de recursos e tentativas de desvalorização das instituições públicas produtoras de conhecimento, por outro.

Em momentos como o que vivemos, a construção coletiva, a solidariedade e a organização como meio para enfrentar as dificuldades e avançar, adquirem ainda mais relevância. Ainda não está definida a nova Editoria, em processo que é feito através de Edital interno à Escola de Administração que se encontra em andamento. Desejo à colega ou colega que assumir a Editoria muita força em sua disposição para enfrentar desafios. Finalmente, agradeço o apoio da Pró-Reitoria de Pesquisa da UFRGS, da CAPES/CNPq e, claro, da Direção da Escola de Administração da UFRGS com a qual a REAd tem vínculo institucional.

\section{Referências}

MARTÍNEZ, G. R.; LARIOS, G. V.; ALBUQUERQUE, A. de la R. Estúdios Organizacionales y Administración: contrastes y complementaridades - caminando hacia el eslabón perdido. Revista Electrónica Forum Doctoral, n. 3, p. 7- 54, 2011. 